\title{
Medical Consultation for the Elderly Patient With Hip Fracture
}

\author{
Richard J. Ackermann, MD
}

Background: This article describes a family physician geriatrician's perspective on the comprehensive management of hip fracture in frail elderly patients. Primary care physicians might be called upon to provide medical consultation for these patients.

Methods: Guidelines were developed by a combination of personal experience in consulting for several hundred elderly patients with hip fracture at a large community hospital, literature review using the key words "hip fractures," "aged," and "aged, 80 and over," and educational presentations for family practice residents.

Results and Conclusions: Elderly patients with hip fracture offer a prime opportunity for comprehensive geriatric assessment. Intertrochanteric fractures are almost always treated with internal fixation, whereas femoral neck fractures can be treated by either fixation or by hemiarthroplasty. Hip fracture should be regarded as a surgical urgency, and generally operation should not be delayed, even if patients have serious comorbidity. The family physician can be instrumental in preparing the patient for surgery, preventing and treating complications, and assisting in the placement and rehabilitation of patients after hospital discharge. (J Am Board Fam Pract 1998;11:366-77.)

As the result of an aging population, family physicians are increasingly likely to participate in the care of elderly patients suffering hip fracture. This devastating orthopedic complication is usually related to underlying osteoporosis and occurs in more than 250,000 Americans per year, with 85 percent of these occurring in patients older than 65 years. Seventy-five percent of hip fractures occur in women, partly because of a higher incidence of hip fracture and increased longevity of women. Advancing age is a powerful risk factor: by 90 years of age, one third of women and one sixth of men will have experienced a hip fracture. An average 80-year-old white woman has an alarming 1 to 2 percent risk of hip fracture per year. Other risk factors for hip fracture include white race, falls, dementia, and a previous hip fracture. ${ }^{1,2}$ The mechanics of falling are altered with age and can cause elderly persons to fall backward, onto their hips, whereas younger fallers usually have more forward momentum and tend to fall on their hands and knees. $^{3}$

Submitted, revised, 2 December 1997.

From the Department of Family and Community Medicine, Mercer University School of Medicine, and the Medical Center of Central Georgia, Macon. Address reprint requests to Richard J. Ackermann, MD, 3780 Eisenhower Parkway, Macon, GA 31206.
Some hip fractures and the falls that precede them are probably preventable. Strategies to detect and treat osteoporosis, especially in high-risk women, can reduce the rate of subsequent hip fracture. Weight-bearing exercise, estrogen, calcium, and other agents are effective. ${ }^{4}$ Comprehensive evaluation of elderly patients complaining of dizziness or falls can prevent injuries, including hip fracture. ${ }^{5}$ Among the most effective interventions to reduce the risk of hip fracture is eliminating medications associated with an increased risk of falls. These drugs include benzodiazepines (especially long-acting agents such as diazepam and chlordiazepoxide), antipsychotics, older antidepressants, and other drugs that can cause orthostatic hypotension or anticholinergic side effects. ${ }^{6}$

Hospital mortality following hip fracture averages 3 to 8 percent, with up to 85 percent of these deaths being caused by pneumonia, congestive heart failure, pulmonary embolism, and myocardial infarction. During the past decade, the in-hospital mortality rate has fallen, but the average length of stay has fallen dramatically. Very few deaths are caused by orthopedic complications of the fracture itself. ${ }^{7}$ One-year mortality averages 20 to 25 percent, which is 12 to 20 percent higher than that expected of patients of similar age and 


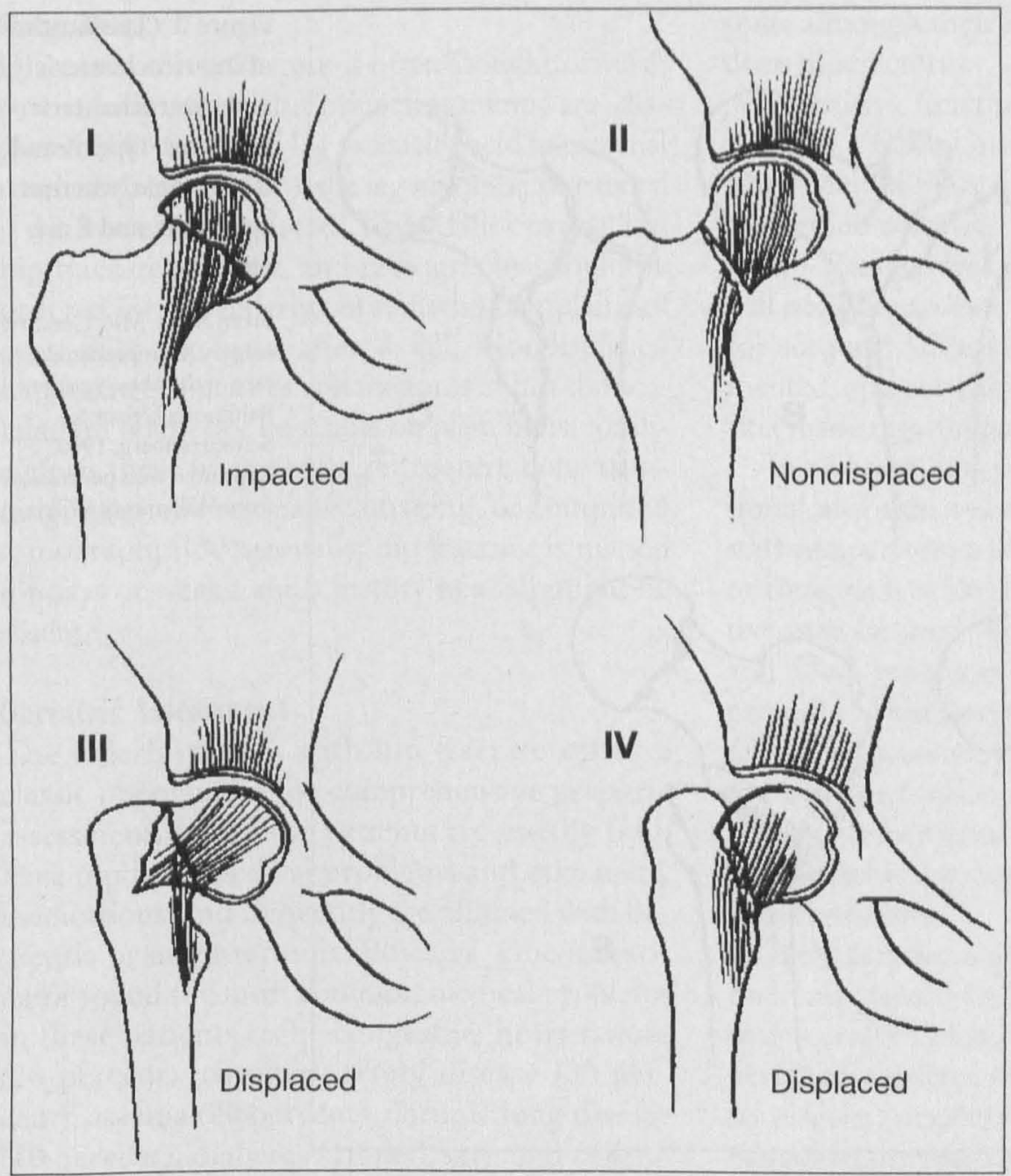

Figure 1. Garden classification of femoral neck fractures.

Type I (impacted) and type II are nondisplaced, whereas type III and type IV are displaced. Types III and IV are difficult to differentiate.

From Katlic MR. Geriatric surgery. Comprehensive care of the elderly patient. Baltmore: Urban \& Schwarzenberg, 1990. Reprinted with permission from Williams \& Wilkins.

sex. ${ }^{2,8,9}$ Hip fracture is all too frequently part of a progressive functional decline, resulting in immobility, institutionalization, and death. ${ }^{10}$

Mortality is higher among patients who are very old, have little social support or live alone, or are in poor general medical condition; institutionalized patients, men, those with dementia, and especially those unable to walk because of the injury also experience higher mortality. ${ }^{11,12}$

In addition to mortality, there are serious morbidities associated with hip fracture. Of previously independent patients, 15 to 25 percent will need nursing home placement for at least 1 year, and less than 30 percent of patients fully regain their prefracture level of function. Aggressive geriatric assessment and rehabilitation will improve outcomes in selected patients. ${ }^{13}$

\section{Methods}

Guidelines were developed by a combination of personal experience in consulting for several hun- dred elderly patients with hip fracture at a large community hospital, literature review, and educational presentations for family practice residents. MEDLINE was searched using the key words "hip fractures," "aged," and "aged, 80 and over."

\section{Types of Hip Fracture}

Fractures of the proximal femur are classified by anatomical location as femoral neck, intertrochanteric, and subtrochanteric types (Figures 1 and 2). ${ }^{2,7,8}$ The latter accounts for less than 5 percent of cases in elderly patients, as it is usually seen in younger patients with high-velocity injuries.

Femoral neck fractures account for approximately one half of hip fractures in the elderly, are intracapsular, and are graded based upon their degree of displacement. Because the blood supply to the femoral head is distally based, there is substantial risk of nonunion and avascular necrosis. Impacted and nondisplaced fractures are generally repaired by internal fixation, whereas displaced 


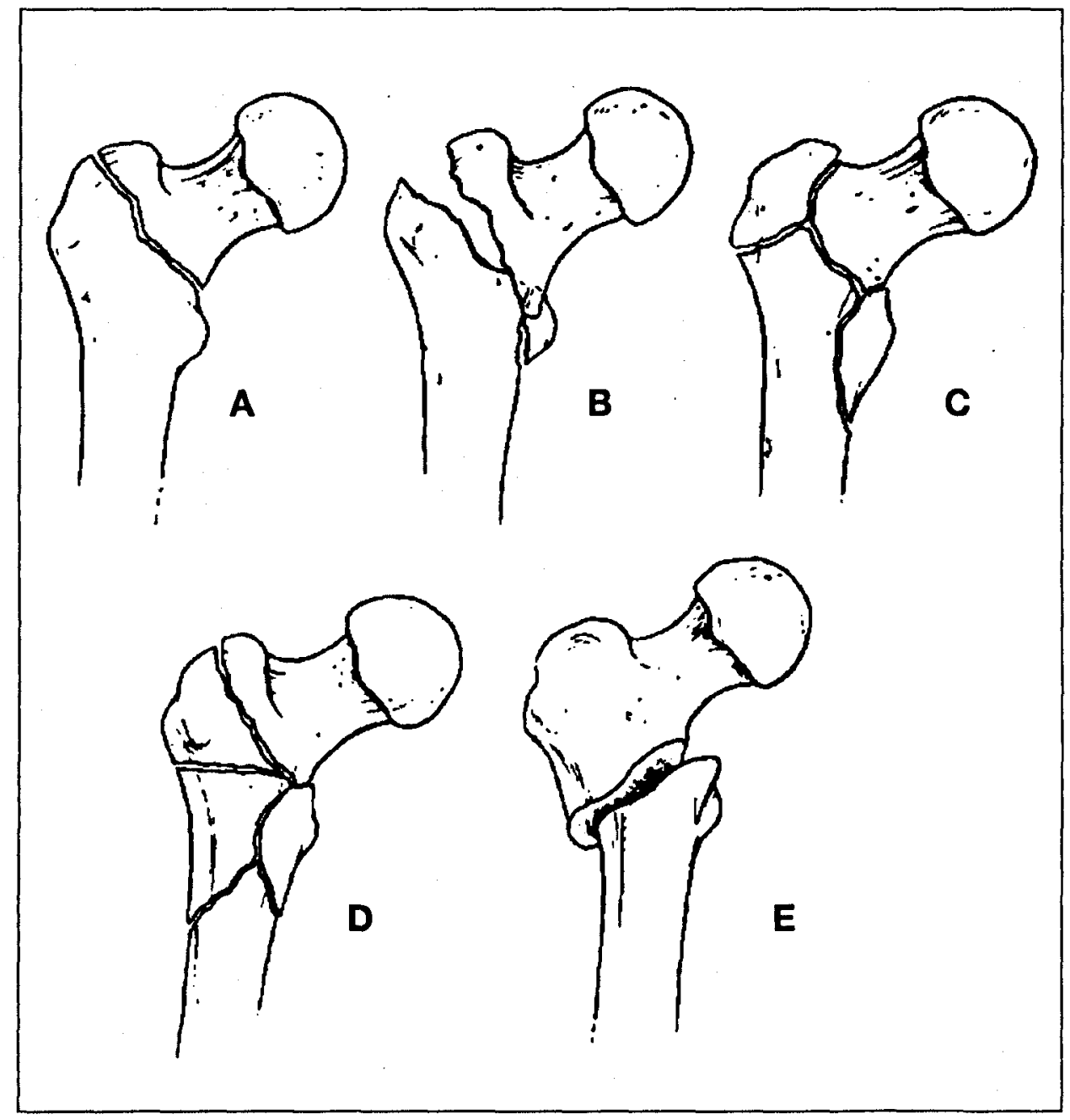

Figure 2. Classification

of intertrochanteric

and subtrochanteric

fractures. Types $A$ and

$B$ are stable, whereas

types $\mathrm{C}, \mathrm{D}$, and $\mathrm{E}$ are unstable.

From Katlic MR. Geriatric surgery. Comprehensive care of the elderly patient. Baltimore: Urban \& Schwarzenberg, 1990. Reprinted with permission from Williams \& Wilkins.

fractures are repaired either by reduction and internal fixation or hemiarthroplasty. Total hip replacement can be appropriate for patients with substantial hip arthritis before the fracture. $2,8,14$

Intertrochanteric fractures comprise the remaining 50 percent of hip fractures. They are usually categorized as either stable or unstable, and all are treated with open reduction and internal fixation. The average patient with intertrochanteric fractures is older than the patient with femoral neck fractures, and although nonunion and avascular necrosis are extremely uncommon, both shortand long-term mortality are higher for this fracture type. ${ }^{2,8,9}$

The elderly patient with a hip fracture should be regarded as having a condition that is surgically urgent. ${ }^{1,15-18}$ Appropriate consultation with subspecialists might be needed, but a single physician should coordinate these efforts to avoid needless delay. Medical problems should be stabilized, but not necessarily optimized, and the patient should generally go to the operating room within 24 hours of the injury. The injured leg may remain in a position of comfort or in light traction (for example, 5 pounds of Buck traction) until surgery. The surgeon will allow many patients to begin weight-bearing immediately after surgery. 2,13,19

In rare circumstances, especially for severely demented, nonambulatory patients, or in those who have medical problems with severe risk of perioperative morbidity and mortality, a nonoperative approach accepting malunion or nonunion might be appropriate. In these cases, a few days of bed rest are followed by bed to chair transfers. For example, Lyon and Nevins ${ }^{20}$ reported good results with a nonoperative approach to hip fracture in 12 severely demented nursing home patients. The long-term results of this approach are unclear; therefore, the physician should be certain of very poor premorbid function before recommending against surgery. 2,21 


\section{Diagnosis}

Diagnosis of hip fracture is often straightforward, particularly when the bone fragments are displaced. The fractured leg is usually held in external rotation (frog position); the leg might be shortened if the fracture is displaced. Trivial falls can result in hip fracture, though, and radiographs should be ordered for any elderly patient who complains of even mild hip pain after a fall. Nondisplaced femoral neck fractures and fractures of just the acetabulum might not be visible on plain films; for diagnosis these fractures might require bone scanning, magnetic resonance imaging, or computed tomography. Occasionally, hip fracture is missed for days or weeks, and a history of a fall might be absent. $^{2}$

\section{Geriatric Assessment}

The elderly patient with hip fracture offers a classic opportunity for comprehensive geriatric assessment. ${ }^{22,23}$ These patients are usually frail, have multiple medical problems and take many medications, and frequently are afflicted with dementia or other terminal illnesses. One investigator found the most common medical problems in these patients to be congestive heart failure (20 percent), coronary artery disease (20 percent), anemia ( 20 percent), chronic lung disease (10 percent), diabetes (10 percent), and central nervous system disorders (10 percent). ${ }^{24}$ As in all cases of trauma, the physician should be alert for other injuries, particularly fractures of the distal femur, pelvis, wrists, clavicle, and ribs, as well as head injuries. Elderly patients whose diagnosis was delayed could be suffering from hypothermia or dehydration.

A key question to ask is, "Why did the parient fall?" For example, the fall might be the presenting symptom of an underlying infection, myocardial ischemia, or gastrointestinal bleeding. A detailed chronology of the fall, from the patient or witnesses, should include history of syncope, lightheadedness, chest pain, palpitations, and leg weakness, as well as a description of environmental circumstances. Many patients can describe previous falls or dizzy spells that led to no or minor injury. ${ }^{25}$ Tinetti et $\mathrm{al}^{5}$ have shown that an intervention involving multiple risk factors (postural hypotension, specific medications, activities of daily living or gait deficits, environmental hazards) can reduce the risk of falling among elderly per- sons, although their study did not specifically address hip fractures.

Cognitive function can be assessed quantitatively by a formal instrument such as the Folstein Mini-Mental State Examination. ${ }^{26}$ How patients perform in activities of daily living is important as well. ${ }^{27}$ Patients lacking decision-making capacity will need a surrogate to provide informed consent for surgery. Advance directives should be documented, and parients should have an explicit decision made regarding resuscitation status.

In addition, it is wise to perform formal nutritional and skin assessments. Nursing or dietary staff can perform a structured dietary assessment, or tools such as the Nutritional Screening Initiative may be used. Body weight, serum albumin, and total lymphocyte count will assist in this process. ${ }^{28}$ Skin assessment for presence of or potential for pressure sores can be accomplished using bedside tools such as the Norton or Braden scales. ${ }^{29}$ Information gained will allow caregivers to take particular care with patients at high risk of skin breakdown.

Although the medical history should be exhaustive, one should be particularly alert for cardiac and cerebrovascular ischemia; heart failure; chronic lung, liver, or renal disease; cardiac valvular disease; peripheral arterial disease; or evidence of gastrointestinal hemorrhage.

Current medications must be carefully assessed; preferably the actual bottles or nursing home orders should be examined. Patients might be suffering from adverse effects of polypharmacy, and this problem should be aggressively managed, with a few caveats. Ineffective or marginally effective drugs can often be discontinued, but drugs that have substantial potential for withdrawal problems are best continued through the perioperative period, with supervised discontinuation attempted later. Similarly, anti-Parkinson drugs should not be abruptly discontinued before surgery; doing so can lead to severe bradykinesia and interfere with recovery. 25,30

Although primary osteoporosis is the cause or a contributing cause in the vast majority of hip fractures, the physician should consider other, more unusual causes, particularly in men or in younger patients. Hyperthyroidism, hyperparathyroidism, alcoholism, and metabolic bone diseases, such as osteomalacia and Paget disease of bone, can cause hip fracture. In addition, a pathologic fracture 
from a solid tumor or bone marrow malignancy such as myeloma is possible. If a secondary cause is suspected, appropriate workup is indicated, and asking the surgeon to obtain a generous bone biopsy would be prudent. Definitive workup can generally be deferred until after surgery.

Adequate analgesia is essential. For patients who have no cognitive impairment, patient-controlled analgesia with morphine is a good choice. Even in demented patients, morphine generally has fewer side effects than meperidine, propoxyphene, or codeine. In one case-control study (mean age 73 years), meperidine was 2.7 times more likely than other narcotics to be associated with postoperative delirium. ${ }^{31}$ Elderly patients might be reluctant to take narcotics, and physicians are sometimes reluctant to prescribe them, but good pain relief allows deeper breaths, improved mobility, and fuller participation with physical therapy. Pain is markedly improved after the fracture is stabilized, and postoperatively, acetaminophen alone often provides good pain control. Narcotics frequently contribute to delirium. ${ }^{32}$

\section{Prevention and Management of Complications Thromboembolism}

Thromboembolism is a common complication of immobility after hip fracture. Without any prophylactic regimen, deep venous thrombosis occurs in 45 to 70 percent and pulmonary embolism in 15 to 20 percent of patients hospitalized for hip fracture. With modern management strategies, combining pharmacologic and physical strategies, rates of proximal venous thrombosis can be reduced to less than 10 percent. ${ }^{33-36}$

Prevention involves much more than systemic anticoagulants. Prompt medical assessment and early operation, early and aggressive rehabilitation, and avoidance of sedatives all contribute to maintaining mobility. The patient and family can be taught to flex and extend the foot of the injured leg, and the patient should periodically draw the heel of the uninjured leg up toward the groin. Postoperatively, the urethral catheter, intravenous lines, oxygen, and so on, should be discontinued as soon as possible. On the evening after surgery, or at least by the next morning, the patient can often sit on the edge of the bed.,25

Other physical modalities are also effective in reducing the risk of thromboembolism. Elastic support stockings can be placed on both legs, and a sequential compression device or venous foot pump can be applied to the uninjured leg. After surgery, most patients can tolerate the sequential compression device on the operated leg as well, which can be continued for 2 to 3 days. 33,34

All patients without contraindications should also receive systemic anticoagulation during the perioperative period (Table 1). ${ }^{35-43}$ Aspirin, dextran, and minidoses of heparin are not effective in preventing thromboembolism. Fully therapeutic doses of warfarin, heparin, or some low-molecularweight heparins are effective in lowering risk. Most patients will require 2.5 to $5.0 \mathrm{mg}$ of daily warfarin to keep the international normalized ratio (INR) at the recommended range of 2.0 to 3.0. Heparin can be dosed to maintain the partial thromboplastin time (PTT) at 1.5 to 2.5 times control or, much more simply, a low-molecularweight heparin can be used without monitoring the PTT. With heparin products, one should probably wait 12 to 24 hours after surgery to start anticoagulation to avoid incisional or deep wound bleeding. The optimal length of anticoagulation necessary after hip fracture repair is unknown, but most authorities recommend 2 to 4 weeks or until reasonable mobility is regained. For patients whose diagnosis of hip fracture has been delayed or who unavoidably must wait several days before surgery, low-molecular-weight heparin can be utilized, holding the dose 12 to 24 hours before surgery and then restarting after surgery. Anticoagulation might need to be stopped or even reversed if there is serious wound or other bleeding. ${ }^{2}$,

Despite such aggressive precautions, acute thromboembolism can occur. Physical examination of the legs is prudent but probably not very helpful. Duplex ultrasound is the diagnostic procedure of choice if there is clinical suspicion of deep venous thrombosis. If the postoperative patient has unexplained dyspnea, hypoxemia, or other chest symptoms, pulmonary embolus should be considered. Perfusion-ventilation lung scanning can be helpful despite its diagnostic limitations. If clinical suspicion of pulmonary embolism is high, the clinician should initiate heparin while the diagnostic process takes place. ${ }^{44,45}$

Some patients will have a hip fracture while already on long-term warfarin anticoagulation. In general, the INR should be reduced to less than 1.5 to prevent excessive blood loss during and after surgery. An efficient method to reduce the 
Table 1. Selected Clinical Trials of Thromboembolism Prophylaxis in Patients With Hip Fractures.

\begin{tabular}{|c|c|c|c|c|c|}
\hline Author, Year & $\begin{array}{l}\text { Study } \\
\text { Characteristics }\end{array}$ & Intervention & $\begin{array}{l}\text { Number of } \\
\text { Patients }\end{array}$ & $\begin{array}{l}\text { DVT } \\
(\%)\end{array}$ & $\begin{array}{c}\text { Major } \\
\text { Bleeding (\%) }\end{array}$ \\
\hline $\begin{array}{l}\text { Sevitt \& Gallagher, } \\
1959\end{array}$ & $\begin{array}{l}\text { Randomized, } \\
\text { unblinded } \\
\text { Controls did not } \\
\text { receive placebo }\end{array}$ & $\begin{array}{l}\text { Coumadin PT } 25-40 \mathrm{sec} \\
\text { Control }\end{array}$ & $\begin{array}{l}150 \\
150\end{array}$ & $\begin{array}{r}3 \\
29\end{array}$ & $\begin{array}{l}3 \\
1\end{array}$ \\
\hline $\begin{array}{l}\text { Powers et al, }{ }^{37} \\
1989\end{array}$ & $\begin{array}{l}\text { Randomized } \\
\text { Aspirin arm } \\
\text { blinded }\end{array}$ & $\begin{array}{l}\text { Coumadin INR } 2.0-2.7 \\
\text { Aspirin } 650 \mathrm{mg} \text { po bid } \\
\text { Placebo }\end{array}$ & $\begin{array}{l}65 \\
66 \\
63\end{array}$ & $\begin{array}{l}20 \\
41 \\
46\end{array}$ & $\begin{array}{r}9 \\
5 \\
10\end{array}$ \\
\hline $\begin{array}{l}\text { Myrvold et al, } \\
1973\end{array}$ & $\begin{array}{l}\text { Randomized, } \\
\text { unblinded }\end{array}$ & $\begin{array}{l}\text { Heparin } 5000-10,000 \mathrm{U} \text { sc bid } \\
\text { Dextran } 70\end{array}$ & $\begin{array}{l}54 \\
83\end{array}$ & $\begin{array}{l}41 \\
36\end{array}$ & $\begin{array}{r}14 \\
9\end{array}$ \\
\hline $\begin{array}{l}\text { Morris \& Mitchell, }{ }^{39} \\
1977\end{array}$ & $\begin{array}{l}\text { Randomized, } \\
\text { unblinded } \\
\text { Controls did not } \\
\text { receive placebo }\end{array}$ & $\begin{array}{l}\text { Heparin } 5000 \mathrm{U} \mathrm{sc} \text { tid } \\
\text { Dipyridamole } 100 \mathrm{mg} \text { tid } \\
\text { Dipyridamole + aspirin } 400 \mathrm{mg} \text { tid } \\
\text { Flurbiprofen } 50 \mathrm{mg} \text { tid } \\
\text { Control }\end{array}$ & $\begin{array}{l}24 \\
24 \\
32 \\
20 \\
76\end{array}$ & $\begin{array}{l}50 \\
63 \\
63 \\
65 \\
64\end{array}$ & 一 \\
\hline $\begin{array}{l}\text { Monreal et al, } \\
1989\end{array}$ & $\begin{array}{l}\text { Randomized, } \\
\text { blinded }\end{array}$ & $\begin{array}{l}\text { LMWH (Kabi 2165) } 5000 \mathrm{U} \text { sc bid } \\
\text { Heparin } 5000 \mathrm{U} \text { sc tid }\end{array}$ & $\begin{array}{l}46 \\
44\end{array}$ & $\begin{array}{l}30 \\
14\end{array}$ & - \\
\hline $\begin{array}{l}\text { Bergqvist et al, } 41 \\
1991\end{array}$ & $\begin{array}{l}\text { Randomized, } \\
\text { unblinded }\end{array}$ & $\begin{array}{l}\text { LMWH (Org 10172) } 750 \text { U sc bid } \\
\text { Dextran } 70\end{array}$ & $\begin{array}{l}139 \\
138\end{array}$ & $\begin{array}{l}10 \\
31\end{array}$ & $\begin{array}{c}\text { More } \\
\text { transfusions in } \\
\text { dextran group }\end{array}$ \\
\hline $\begin{array}{l}\text { Gerthart et al, }{ }^{42} \\
1991 \\
\text { Gent et al, }{ }^{43} \\
1996\end{array}$ & $\begin{array}{l}\text { Randomized, } \\
\text { unblinded } \\
\text { Randomized, } \\
\text { blinded }\end{array}$ & $\begin{array}{l}\text { LMWH (Org 10172) } 750 \mathrm{U} \text { sc bid } \\
\text { Coumadin PT } 1.5 \times \text { control } \\
\text { LMWH (Orgaran) } 750 \mathrm{U} \mathrm{sc} \text { bid } \\
\text { Aspirin } 100 \mathrm{mg} \text { po bid }\end{array}$ & $\begin{array}{l}132 \\
131 \\
125 \\
126\end{array}$ & $\begin{array}{r}5 \\
11 \\
28 \\
44\end{array}$ & $\begin{array}{l}6 \\
4 \\
1 \\
3\end{array}$ \\
\hline
\end{tabular}

Note: DVT - deep venous thrombosis, PT - prothrombin time, sc - subcutaneous, bid - twice daily, tid - three times daily, INR - international normalized ratio, LMWH - low-molecular-weight heparin.

INR is to administer small subcutaneous doses of vitamin $\mathrm{K}(0.5$ to $2.0 \mathrm{mg})$ and reevaluate the INR at 6- to 12-hour intervals. If the patient is at very high risk of thromboembolism, low-molecularweight heparin can also be prescribed postoperatively until warfarin has returned the INR to the desired range. ${ }^{46}$

\section{Delirium}

Delirium, an acute confusional state characterized by inattention and varying levels of consciousness, is seen in up to 50 percent of patients hospitalized for hip fracture. Its presence is associated with an increase in hospital mortality, length of stay, and institutionalization. It is nearly universal in patients with cognitive impairment. Anesthetic choice, in particular general versus spinal methods, does not influence the rate of delirium. ${ }^{47-50}$

Prevention of delirium includes careful and repetitive assessment of medications. Opiates and phenothiazines used to treat pain and nausea can cause severe agitation and confusion, as can benzodiazepines used to help sleeplessness. ${ }^{31}$ Patients should be allowed to wear their own clothes, glasses, and hearing aids and surround themselves with familiar objects. Unnecessary room relocation and disturbances should be kept to a minimum. A family member can stay with the patient, especially at night. ${ }^{51}$

When delirium does occur, it should be regarded as a medical emergency, and a thorough assessment is indicated. ${ }^{26,52}$ Evaluation should consider medication side effects, hypoxemia, anemia, electrolyte disturbances, myocardial ischemia, pain, pneumonia, and pulmonary embolus, among others. Laboratory tests, such as complete blood counts, chemistry panel, electrocardiogram, and pulse oximetry, are often useful, but brain computed tomography is rarely of any diagnostic help. Treatment of delirium is directed at correcting the underlying cause, but small doses of haloperidol or lorazepam might be necessary in severe cases. These drugs should be withdrawn as the delirium resolves. ${ }^{53}$

\section{Urinary Tract Infection and Urinary Retention}

Urinary traction infection is the most common bacterial infection in hospitalized elderly persons, and it is often related to the use of urethral catheters. Asymptomatic bacteriuria can be found 
in approximately 15 percent of communitydwelling elderly persons and up to 30 percent of nursing home patients. When an invasive procedure such as hip surgery is planned, treatment of bacteriuria is reasonable to transiently reduce the risk of bacteremia. ${ }^{54}$ In this case, the patient should receive a standard treatment course of antibiotics, not just routine postoperative antibiotic prophylaxis.

The urinary catheter should be removed soon after surgery, unless the patient clearly needs hourly measurement of urinary output. Many patients will experience transient urinary retention as a result of pain, opiates, anesthesia, and other factors, but evidence does not support leaving the catheter in place longer than 24 to 36 hours to prevent this problem. Getting patients upright and out of bed to a bedside commode will often allow them to successfully empty their bladder. ${ }^{25}$ Intermittent catheterization can be done as needed, and the clinician can check whether excessive sedation or anticholinergic drugs might be contributing to retention. If retention persists, an indwelling catheter should be reinserted for 24 to 48 hours and then withdrawn again. ${ }^{55,56}$

\section{Pressure Sores}

A pressure sore dramatically complicates the care of a patient with hip fracture and is associated with a marked increase in length of stay and mortality. A thorough initial physical examination for areas of early or established pressure sores should be done, although doing so can be difficult for sacral locations. Aggressive mobilization is the most effective preventive method. Patients at very high risk or with established pressure sores need an interdisciplinary approach, often including consultation with an enterostomal nurse who has experience in ulcer management (Table 2). ${ }^{29,57}$

\section{Heart Disease}

Heart failure requires aggressive evaluation and management, although extensive diagnostic workup, including echocardiography and other modalities, should not usually delay surgery unless the patient's cardiac status has clearly decompensated. Physical examination, chest radiographs, electrocardiogram, pulse oximetry, and electrolytes can be rapidly obtained. Generally, all heart failure medications should be continued through surgery, including oral doses just before the procedure. Sup-
Table 2. Guidelines for the Prevention

\section{of Pressure Sores.}

Skin care and early treatment

Systematically inspect the skin of all patients at risk on a daily basis

Cleanse the skin whenever it is soiled and at routine intervals

Minimize environmental factors leading to skin drying or to excessive skin moisture

Avoid massage over bony prominences

Minimize friction and shear injuries by proper positioning, transferring, and turning techniques

Develop an appropriate plan of nutritional support

Maintain or enhance mobility

\section{Mechanical loading and support surfaces}

Reposition bed-bound patients at least every 2 hours

Use pillows and foam wedges to keep bony prominences from direct contact with one another

For bed-bound patients, use devices that totally relieve pressure on the heels

For side-lying patients, avoid positioning directly on the trochanter

Maintain the head of the bed at the lowest degree of elevation consistent with overall needs

Use lifting devices, such as trapeze, or bed linens for patients who cannot assist with transfers and position changes

High-risk patients should lie on pressure-reducing devices, such as foam, static air, alternating air, gel, or water mattresses

Patients should not sit uninterrupted in a chair or wheelchair, and chair-bound patients should use pressure-reducing devices, but not donut-type devices

Adapted from the Agency for Health Care Policy and Research. ${ }^{29}$

plemental oxygen is reasonable. Diuretic doses might need careful titration for a few days. For patients with severe systolic dysfunction, close coop- eration with the anesthesiologist is essential. Surgery should be delayed in unstable patients; selected patients might require invasive hemodynamic monitoring in the perioperative period. ${ }^{58,59}$

A routine preoperative electrocardiogram is essential, but cardiac enzymes are not. Routine oxygen supplementation for patients with stable coronary artery disease is usually given. Some evidence suggests that perioperative $\beta$-adrenergic blockade might reduce the incidence of cardiovascular complications. ${ }^{60}$ Postoperative myocardial infarction can be difficult to diagnose and has a high mortality. The most common symptom in the elderly is dyspnea. Management of postoperative myocardial infarction is difficult, partly because thrombolysis is contraindicated. ${ }^{58,59}$

Valvular heart disease, particularly aortic stenosis, is relatively common in the very old patient. 
Patients with established aortic stenosis or a murmur suggestive of aortic stenosis should not have surgery delayed. The anesthesiologist should be notified of this high-risk situation, and echocardiography can be helpful as long as it does not delay surgery.

\section{Stroke}

Patients who have had a stroke or transient ischemic attack, as well as those who have considerable carotid stenosis, are at increased risk of perioperative stroke. Nevertheless, unless acute stroke is the cause of the fall and fracture, surgery should proceed. Workup of the carotid arteries with ultrasound imaging might be important, but it can wait until after the hip fracture repair. The physician should review any serious situation with the anesthesiologist. Even in the face of acute stroke, hip surgery can often be accomplished within a few days.

\section{Parkinsonism}

Occasionally, patients with Parkinson disease or other causes of parkinsonism will fracture their hip as a result of progressive stiffness, bradykinesia, and orthostatic hypotension. To avoid severe and sometimes abrupt dyskinesias, carbidopa-levodopa (Sinemet) should never be abruptly withdrawn in the perioperative period. These patients require special attention during rehabilitation. In addition to their severe motor problems, they also are at increased risk for aspiration pneumonia and are frequently demented. Prognosis is markedly impaired in patients with Parkinson disease who suffer hip fracture. ${ }^{25}$

\section{Anemia, Fluids, and Electrolytes}

An average of 500 to $1000 \mathrm{cc}$ of blood is lost into the thigh surrounding the hip fracture; other injuries and the hip operation itself can also contribute to anemia. In large case series, more than 50 percent of patients were transfused during the hospitalization. ${ }^{7}$ There are no clear levels of hemoglobin or hematocrit that mandate transfusion. In the first hours after injury, the hematocrit is a poor indicator of circulating red cell mass, and preoperative transfusion might be indicated at higher hemoglobin levels. Elderly patients with vascular insufficiency to the brain, myocardium, kidney, or other organs can require higher hematocrits for adequate oxygen delivery.
Fluid replacement is indicated, but parenteral fluids are generally needed for only 24 to 48 hours. Volume depletion should be gently corrected, using such clinical signs as weight, urine specific gravity, and blood urea nitrogen. Elderly persons have an impaired thirst response to dehydration and cannot concentrate the urine as effectively as younger patients. On the other hand, many frail, low-weight women might drink only 800 to $1200 \mathrm{~mL}$ of fluids per day, and providing the typical intravenous rate of $125 \mathrm{~mL} / \mathrm{h}$ could lead to volume overload. A reasonable intravenous fluid is 5 percent dextrose in lactated Ringers solution at 50 to $100 \mathrm{~mL} / \mathrm{h}$ with supplemental potassium, if needed. The patient can generally begin oral intake several hours after surgery, and most patients will not need intravenous fluids beyond the first postoperative day.

A common electrolyte abnormality in patients with hip fracture is hyponatremia. ${ }^{25}$ Although this abnormality has many causes, including diuretics and other drugs, as well as heart, liver, renal, adrenal, or thyroid disease, the most common reason is excessive antidiuretic hormone effect. Pain, anesthesia, narcotics, and especially nausea are potent stimulants to antidiuretic hormone release, which causes the kidney to retain free water and dilute total body sodium. Treatment of the underlying causes allows the body to correct this problem. Normal saline infusion will not help, but occasionally modest fluid restriction might be necessary. ${ }^{61}$

Severe hypokalemia should be corrected before surgery, but high concentrations or volumes of potassium-containing fluids are dangerous and are not indicated unless the patient has serious arrhythmias. Oral supplements are safe and might be needed for several days. Diuretics at excessive doses should be withheld or their dosages reduced. ${ }^{62}$

Hyperkalemia is less common and is usually due to renal disease or a combination of drugs that raise serum potassium. These drugs include potassium supplements, potassium-sparing diuretics, angiotensin-converting enzyme inhibitors, $\beta$ blockers, trimethoprim, and nonsteroidal antiinflammatory drugs. Stopping one or two of the offending drugs is usually adequate. ${ }^{63}$

\section{Seizures}

Patients with seizure disorders should continue taking anticonvulsants, even up to the hour of 
surgery. ${ }^{25}$ Drug levels should be measured, with the caveat that many elderly persons have seizures well controlled with serum levels below recommended therapeutic ranges, probably as a result of altered drug-protein binding. Oral anticonvulsants should be restarted soon after surgery. If oral intake cannot be maintained, phenytoin can be safely given parenterally as fosphenytoin. ${ }^{64}$ Phenobarbital use will increase the dose of warfarin needed to achieve anticoagulation.

If a seizure occurs, a thorough evaluation is indicated, but aggressive intravenous anticonvulsants are not indicated unless the patient is in status epilepticus. Consideration should be given to withdrawal syndromes from alcohol, benzodiazepines, or barbiturates. For patients who are heavy alcohol users, prophylactic treatment with benzodiazepines, using established protocols, can be life-saving. ${ }^{65,66}$

\section{Orthopedic Complications}

It is routinely advised that perioperative antibiotics, usually a first-generation cephalosporin, be given every 6 to 12 hours. Infectious disease guidelines recommend only one or two doses, but most orthopedic surgeons prefer to continue antibiotics for about 36 hours. ${ }^{67-70}$ The recent Dutch Trauma Trial found that, compared with placebo, a single $2-\mathrm{g}$ intravenous dose of ceftriaxone reduced the rate of wound infection from 8.3 percent to 3.6 percent. In this trial urinary and respiratory nosocomial infections were also reduced by 77 percent. ${ }^{71}$ With antibiotic prophylaxis, the incidence of superficial wound infections is generally less than 2 percent, and deep wound infections, which can require removing the hardware, are rare but devastating. ${ }^{2,72-74}$

On the other hand, postoperative fever is very common in the first few days after hip surgery. Fever should not be ignored, but infection should be diagnosed using appropriate criteria. Physical examination of the lungs, skin, abdomen, and wound are important, and white cell count, urinalysis, and chest radiograph can be helpful.

Mechanical complications are surprisingly frequent, partly because of underlying osteoporotic bone, but they usually occur months to years after surgery. Loss of fixation, nonunion, or osteonecrosis can eventually occur in up to 50 percent of patients. These orthopedic complications generally cause hip pain, and some patients will require re- operation. With hemiarthroplasty, the prosthesis can become loose or dislocated. Orthopedic consultation will be necessary in these cases. Other orthopedic complications include myositis ossificans and septic arthritis. ${ }^{75,76}$

\section{Discharge Options}

Elderly patients now spend far less time than in previous years recovering from a hip fracture in acute care hospitals. Lengths of stay fall dramatically when the patient is taken to the operating room early and when vigorous rehabilitation occurs. The physician, however, should not become preoccupied with length of stay as a major outcome. ${ }^{2}$ The most important outcomes for elderly patients who break their hips are mortality and functional recovery. Measuring function at hospital discharge is not very valuable; $a$ better assessment is function at 6 months. ${ }^{77}$

Most patients will not be able to walk independently at the time of hospital discharge, but eventually 50 percent will regain their previous level of ambulation. As many as 20 percent will become completely nonambulatory, which severely limits functional recovery and independent living. It has been shown that since the prospective payment system began, more elderly persons with hip fracture are remaining in nursing homes 1 year after the fracture. ${ }^{2}$

A recent rigorous, controlled trial showed that, compared with less intense care provided in a nursing home, rehabilitation of elderly hip fracture patients in a Medicare certified rehabilitation hospital offered no long-term functional advantage. ${ }^{78}$ Many frail elderly persons will not be able to tolerate the 3 hours' minimum therapy required by Medicare in rehabilitation hospitals. Aggressive rehabilitation might not have lasting benefits. For many patients rehabilitation at home, with visits by physical therapists, nurses, and home health aides, might be appropriate, but at least one dedicated family member must be present. Alternatively, patients can undergo rehabilitation in subacute beds affiliated with nursing homes, with transition to a less restrictive environment as independence is regained. ${ }^{19}$

Selected patients will benefit from a properly fitted cane (or four-footed cane), which should have a new 1-inch rubber tip(s) and be long enough so that the elbow is at 20 to 30 degrees of flexion when held at the side. The patient should 
grip the cane with the hand opposite the injured hip. If a cane is not practical because of upper body weakness or instability, a walker might be appropriate. The walker should be advanced 8 to 12 inches, then the weak leg advanced, and finally the strong leg. Crutches are not appropriate. To climb stairs, the patient should go up with the strong leg first and step down with the injured leg first. (Up with the good, down with the bad.) $)^{19}$

Because it often takes several days to evaluate the discharge options and get the patient, family, physicians, and other team members to agree upon a plan, the discharge planning service should be involved from the first hospital day. Doing so allows paperwork to be signed, facilities visited, patients interviewed, and so on, before discharge is imminent. A skillful discharge planner is the family physician's close ally.

The family physician should assist the orthopedic surgeon in providing explicit discharge instructions to the patient. Medications, with dosages, need to be clearly defined. Someone must be designated to monitor the INR if warfarin is prescribed. Home health agencies will provide nursing, aide, and physical therapy services as well as draw blood samples. If the patient is being transferred to the care of another physician, copies of the discharge summary, advance directives, and important laboratory and imaging studies should be forwarded. A physician-to-physician telephone call can prevent misunderstandings.

\section{Conclusions}

Comprehensive medical evaluation of elderly patients with acute hip fractures can improve the quality of medical care and probably decrease costs. Evaluation must emphasize functional assessment and the common geriatric syndromes, such as dementia, delirium, incontinence, polypharmacy, and falls. The family physician can play a crucial role in orchestrating the complex medical and social needs of these frail patients.

\section{References}

1. Grisso JA, Kaplan F. Hip fractures. In Hazzard WR, Bierman EL, Blass JP, Ettinger WH, Halter JB, editors. Principles of geriatric medicine and gerontology. 3rd ed. New York: McGraw-Hill, 1994.

2. Zuckerman JD. Hip fracture. N Engl J Med 1996; 334:1519-25.

3. Cummings SR, Nevitt MC. A hypothesis: the causes of hip fractures. J Gerontol 1989;44:M107-11.
4. Bellantoni MF. Osteoporosis prevention and treatment. Am Fam Physician 1996;54:986-92, 995-6.

5. Tinetti ME, Baker DI, McAvay G, Claus EB, Garrett $\mathrm{P}$, Gottschalk $M$, et al. A multifactorial intervention to reduce the risk of falling among elderly people living in the community. $\mathrm{N}$ Engl J Med 1994; 331;821-7.

6. Ray WA, Griffin MR, Schaffner W, Baugh DK, Melton LJ 3d. Psychotropic drug use and the risk of hip fracture. N Engl J Med 1987;316:363-9.

7. Zuckerman JD, Sakales SR, Fabian DR, Frankel VH. Hip fractures in geriatric patients. Results of an interdisciplinary hospital care program. Clin Orthop 1992jJan(274):213-25.

8. Lu-Yao GL, Baron JA, Barrett JA, Fisher ES. Treatment and survival among elderly Americans with hip fractures: a population-based study. Am J Public Health 1994;84:1287-91.

9. Thorngren M, Nilsson LT, Thorngren KG. Prognosis-determined rehabilitation of hip fractures. Compr Gerontol A 1988;2:12-7.

10. Marottoli RA, Berkman LF, Cooney LM Jr. Decline in physical function following hip fracture. J Am Geriatr Soc 1992;40:861-6.

11. Ceder L, Thorngren KG, Wallden B. Prognostic indicators and early home rehabilitation in elderly patients with hip fractures. Clin Orthop 1980; Oct(152):173-84.

12. Wallace RG, Lowry JH, McLeod NW, Mollan RA. A simple grading system to guide the prognosis after hip fracture in the elderly. $\mathrm{Br}$ Med J Clin Res Ed 1986;293:665.

13. Ceder L, Stromqvist B, Hansson LI. Effects of strategy changes in the treatment of femoral neck fractures during a 17-year period. Clin Orthop 1987; $\operatorname{May}(218): 53-7$.

14. Young Y, German P, Brant L, Kenzora J, Magaziner $J$. The predictors of surgical procedure and the effects on functional recovery in elderly with subcapital fractures. J Gerontol A Biol Sci Med Sci 1996;51:M158-64.

15. Gilchrist WJ, Newman RJ, Hamblen DL, Williams BO. Prospective randomised study of an orthopaedic geriatric inpatient service. BMJ 1988;297: 1116-8.

16. Sikorski JM, Davis NJ, Senior J. The rapid transit system for patients with fractures of proximal femur. Br Med J Clin Res Ed 1985;290:439-43.

17. Farnworth MG, Kenny P, Shiell A. The costs and effects of early discharge in the management of fractured hip. Age Ageing 1994;23:190-4.

18. Hoenig H, Rubenstein LV, Sloane R, Horner R, Kahn K. What is the role of timing in the surgical and rehabilitative care of community-dwelling older persons with acute hip fracture? Arch Intern Med 1997;157:513-20.

19. Brummel-Smith K. Rehabilitation. In: Cassel $\mathrm{CK}$, Dohen HJ, editors. Geriatric medicine. 3rd ed. New York: Springer, 1997.

20. Lyon LJ, Nevins MA. Management of hip fractures 
in nursing home patients: to treat or not to treat? $\mathrm{J}$ Am Geriatr Soc 1984;32:391-5.

21. Winter WG. Nonoperative treatment of proximal femoral fractures in the demented, nonambulatory patient. Clin Orthop 1987;May(218):97-103.

22. Gustafson $Y$, Brannstrom B, Berggren D, Ragnarsson JI, Sigaard J, Bucht G, et al. A geriatric-anesthesiologic program to reduce acute confusional states in elderly patients treated for femoral neck fractures. J Am Geriatr Soc 1991;39:655-62.

23. Kennie DC, Reid J, Richardson IR, Kiamari AA, Kelt C. Effectiveness of geriatric rehabilitative care after fractures of the proximal femur in elderly women: a randomized clinical trial. BMJ 1988; 297:1083-6.

24. Burnside JW. Orthopaedics and rheumatology. In Kammerer WS, Gross RJ, editors. Medical consultation: the internist on surgical, obstetric, and psychiatric services. 2nd ed. William \& Wilkins, 1990.

25. Gordon $M$. Restoring functional independence in the older hip fracture patient. Geriatrics 1989;44 (12):48-53, 56, 59.

26. Folstein MF, Folstein SE, McHugh PR. "Mini-mental state." A practical method for grading the cognitive state of patients for the clinician.J Psychiatr Res 1975:12:189-98.

27. Katz S. Assessing self-maintenance: activities of daily living, mobility, and instrumental activities of daily living. J Am Geriatr Soc 1983;31:721-7.

28. Reuben DB, Greendale GA, Harrison GG. Nutrition screening in older persons. J Am Geriatr Soc 1995;43:415-25.

29. Panel for the Prediction and Prevention of Pressure Ulcers in Adults. Pressure ulcers in adults - vol 2. Prediction and prevention. Clinical practice guideline no 3. Rockville, MD: US Department of Health and Human Services, Public Health Service, Agency for Health Care Policy and Research, 1992. (AHCPR publication no. 92-0047.)

30. Ackermann RJ, Meyer von Bremen GB. Reducing polypharmacy in the nursing home: an activist approach. J Am Board Fam Pract 1995;8:195-205.

31. Marcantonio ER, Juarez G, Goldman L, Mangione CM, Ludwig LE, Lind L, et al. The relationship of postoperative delirium with psychoactive medications. JAMA 1994;272:1518-22.

32. Acute Pain Management Guideline Panel. Acute pain management: operative or medical procedures and trauma. Clinical practice guideline no 1 . Rockville, MD: US. Department of Health and Human Services, Public Health Service, Agency for Health Care Policy and Research, 1992. (AHCPR publication no. 92-0032.)

33. Hull RD, Raskob GE, Gent M, McLoughlin D, Julian D, Smith FC, et al. Effectiveness of intermittent pneumatic leg compression for preventing deep vein thrombosis after total hip replacement. JAMA 1990;263:2313-7.

34. Stranks GJ, MacKenzie NA, Grover ML, Fail T. The A-V Impulse System reduces deep-vein throm- bosis and swelling after hemiarthroplasty for hip fracture. J Bone Joint Surg Br 1992;74-B:775-8.

35. Imperiale TF, Speroff T. A meta-analysis of methods to prevent venous thromboembolism following total hip replacement. JAMA 1994;271:1780-5.

36. Sevitt S, Gallagher NG. Prevention of venous thrombosis and pulmonary embolism in injured patients. Lancet 1959;2:981-989.

37. Powers PJ, Gent M, Jay RM, Julian DH, Turpie AG, Levine $M$, et al. A randomized trial of less intense postoperative warfarin or aspirin therapy in the prevention of venous thromboembolism after surgery for fractured hip. Arch Intern Med 1989;149:771-4.

38. Myrvold HE, Persson JE, Svensson B, Wallensten S, Vikterlof KJ. Prevention of thrombo-embolism with dextran 70 and heparin in patients with femoral neck fractures. Acta Chir Scand 1973;139:609-16.

39. Morris GK, Mitchell JR. Preventing venous thromboembolism in elderly patients with hip fractures: studies of low-dose heparin, dipyridamole, aspirin, and flurbiprofen. Br Med J 1977;1:535-7.

40. Monreal M. Lafoz E, Navarro A, Granero X, Caja V, Caceres $\mathrm{E}$, et al. A prospective double-blind trial of a low molecular weight heparin once daily compared with conventional low-dose heparin three times daily to prevent pulmonary embolism and venous thrombosis in patients with hip fracture. J Trauma 1989; 29:873-5.

41. Bergqvist D, Kettunen K, Fredin H, Fauno P, Suomalainen $\mathrm{O}$, Soimakallio $\mathrm{S}$, et al. Thromboprophylaxis in patients with hip fractures: a prospective; randomized, comparative study between Org 10172 and dextran 70. Surgery 1991;109:617-22.

42. Gerhart TN, Yett HS, Robertson LK, Lee MA, Smith M, Salzman EW. Low-molecular-weight heparinoid compared with warfarin for prophylaxis of deep-vein thrombosis in patients who are operated on for fracture of the hip. A prospective, randomized trial. J Bone Joint Surg Am 1991;7:494-502.

43. Gent M, Hirsh J, Ginsberg JS, Powers PJ, Levine MN, Geerts WH, et al. Low-molecular-weight heparinoid orgaran is more effective than aspirin in the prevention of venous thromboembolism after surgery for hip fracture. Circulation 1996;93:80-4.

44. Bergus GR, Barloon TS, Kahn D. An approach to diagnostic imaging of suspected pulmonary embolism. Am Fam Physician 1996;53:1259-66.

45. Agnelli G. Anticoagulation in the prevention and treatment of pulmonary embolism. Chest 1995;107 (1 Suppl):39S-44S.

46. Kearon C, Hirsh J. Management of anticoagulation before and after elective surgery. $\mathrm{N}$ Engl J Med 1997;336:1506-11.

47. Williams-Russo P, Urquhart BL, Sharrock NE, Charlson ME. Post-operative delirium: predictors and prognosis in elderly orthopedic patients. J Am Geriatr Soc 1992;40:759-67.

48. Bigler D, Adelhoj B, Petring OU, Pederson NO, Busch P, Kalhke P. Mental function and morbidity after acute hip surgery during spinal and general 
anaesthesia. Anaesthesia 1985;40:672-6.

49. Hosking MP, Lobdell CM, Warner MA, Offord KP, Melton LJ 3d. Anaesthesia for patients over 90 years of age. Outcomes after regional and general anaesthetic techniques for two common surgical procedures. Anaesthesia 1989;44:142-7.

50. Covert CR, Fox GS. Anaesthesia for hip surgery in the elderly. Can J Anaesth 1989;36:311-9.

51. Creditor MC. Hazards of hospitalization of the elderly. Ann Intern Med 1993;118:219-23.

52. Inouye $\mathrm{SK}$, van Dyck CH, Alessi CA, Balkin S, Siegal AP, Horwitz RI. Clarifying confusion: the confusion assessment method. A new method for detection of delirium. Ann Intern Med 1990;113:941-8.

53. Inouye SK. The dilemma of delirium: clinical and research controversies regarding diagnosis and evaluation of delirium in hospitalized elderly medical patients. Am J Med 1994;97:278-88.

54. Nicolle LE. Diagnosis and management of asymptomatic bacteriuria in the older patient. Clin Geriatr 1996;4(1):19-20,25-27,31.

55. Hozack WJ, Carpiniello V, Booth RE Jr. The effect of early bladder catheterization on the incidence of urinary complications after total joint replacement. Clin Orthop 1988;un(231):79-82.

56. Michelson JD, Lotke PA, Steinberg ME. Urinarybladder management after total joint-replacement surgery. N Engl J Med 1988;319:321-6.

57. Treatment of Pressure Ulcers Guideline Panel. Treatment of pressure ulcers. Clinical practice guideline, no 15. Rockville, MD: US Department of Health and Human Services, Public Health Service, Agency for Health Care Policy and Research, 1994. (AHCPR publication no. 95-0652.)

58. Weitz $\mathrm{HH}$. Noncardiac surgery in the elderly patient with cardiovascular disease. Clin Geriatr Med 1990;6:511-29.

59. Mangano DT, Goldman L. Preoperative assessment of patients with known or suspected coronary disease. N Engl J Med 1995;333:1750-6.

60. Mangano DT, Layug EL, Wallace A, Tateo I. Effect of atenolol on mortality and cardiovascular morbidity after noncardiac surgery. Multicenter Study of Perioperative Ischemia Research Group. N Engl J Med 1996;335:1713-20.

61. Steele A, Gowrishankar M, Abrahamson S, Mazer CD, Feldman RD, Halperin ML. Postoperative hyponatremia despite near-isotonic saline infusion: a phenomenon of desalination. Ann Intern Med 1997;126:20-5.

62. Antonelli-Incalzi R, Gemma A, Capparella O, Terranova L, Sanguinetti C, Carbonin PU. Post-operative electrolyte imbalance: its incidence and prognostic implications for elderly orthopaedic patients. Age Ageing 1993;22:325-31.

63. Perazella MA. Hyperkalemia in the elderly. Clin Geriatr 1997;5(3):78-80,84-8,93,96-100,105,106.

64. Browne TR, Kugler AR, Eldon MA. Pharmacology and pharmacokinetics of fosphenytoin. Neurology 1996;46(6 Suppl 1):\$2-7.

65. Yost DA. Alcohol withdrawal syndrome. Am Fam Physician 1996;54:657-64, 669.

66. Lohr RH. Treatment of alcohol withdrawal in hospitalized patients. Mayo Clin Proc 1995;70;777-82.

67. Boyd RJ, Burke JF, Colton T. A double-blind clinical trial of prophylactic antibiotics in hip fractures. $J$ Bone Joint Surg AM 1973;55;1251-8.

68. Burnett JW, Gustilo RB, William DN, Kind AC. Prophylactic antibiotics in hip fracture. J Bone Joint Surg Am 1980;62:457-62.

69. Buckley R, Hughes GN, Snodgrass T, Huchcroft SA. Perioperative cefazolin prophylaxis in hip fracture surgery. Can J Surg 1990;33:122-7.

70. Bodoky A, Neff U, Heberer M, Harder F. Antibiotic prophylaxis with two doses of cephalosporin in patients managed with internal fixation for a fracture of the hip. J Bone Joint Surg Am 1993;75:61-5.

71. Boxma H, Broekhuizen T, Patka P, Oosting H. Randomised controlled trial of single-dose antibiotic prophylaxis in surgical treatment of closed fractures: the Dutch Trauma Trial. Lancet 1996;347:1133-7.

72. Kaiser AB. Antimicrobial prophylaxis in surgery. $N$ Engl J Med 1986;315:1129-38.

73. Maguire JH. Advances in the control of perioperative sepsis in total joint replacement. Rheum Dis Clin North Am 1988;14:519-35.

74. Nasser S. Prevention and treatment of sepsis in total hip replacement surgery. Orthop Clin North Am 1992;23:265-77.

75. Holmberg $S$, Kalen $R$, Thorngren KG. Treatment and outcome of femoral neck fractures. An analysis of 2418 patients admitted from their own homes. Clin Orthop 1987;May(218):42-52.

76. Eastwood HD. The social consequences of surgical complications for patients with proximal femoral fractures. Age Ageing 1993;22:360-4.

77. Evans JG. Services for patients with proximal femoral fracture. In Evans JG, William TF, editors. Oxford textbook of geriatric medicine. Oxford: Oxford University Press, 1992.

78. Kramer AM, Steiner JF, Schlenker RE, Eilertsen TB, Hrincevich CA, Tropea DA, et al. Outcomes and costs after hip fracture and stroke. A comparison of rehabilitation settings. JAMA 1997;277:396-404. 